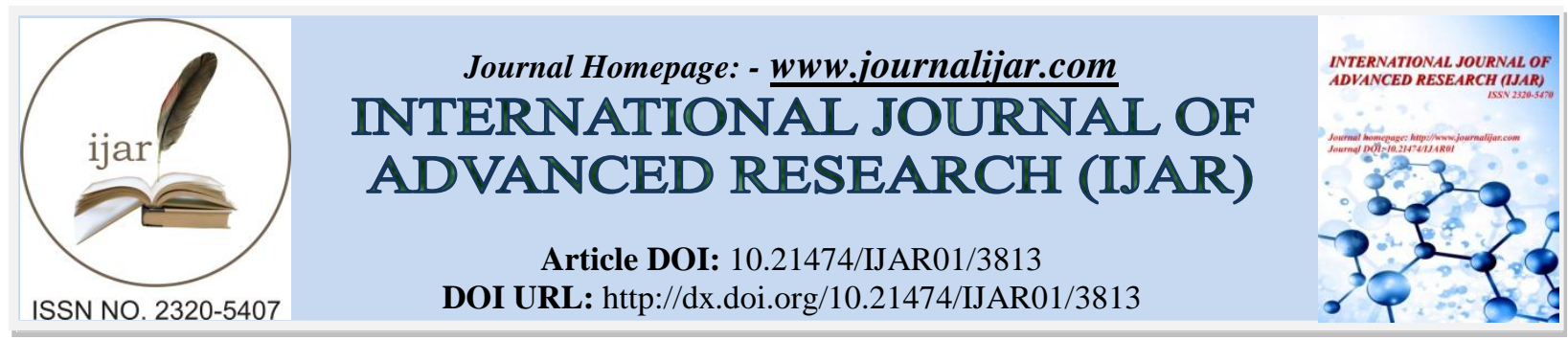

RESEARCH ARTICLE

\title{
GROSS CHANGES SEEN IN THE HEART SAMPLES OF DCM PATIENTS FROM NORTH INDIA - A CADAVERIC STUDY.
}

\section{Dr. Prasenjit Bose ${ }^{1}$ and Barkha Singh ${ }^{2}$.}

1. Assistant Professor, Department of Anatomy, Raipur Institute of Medical Sciences, Raipur (Chhattisgarh).

2. Research Scholar, Cytogenetic Lab, Department of Anatomy, Institute of Medical Sciences, Banaras Hindu University, Varanasi (U.P).

\section{Manuscript Info}

\section{Manuscript History}

Received: 07 February 2017

Final Accepted: 01 March 2017

Published: April 2017

Key words:-

Dilated Cardiomyopathy, Right Atrium,

Left Atrium, Right Ventricle, Left

Ventricle and Vernier Caliper

\section{Abstract}

Dilated cardiomyopathy is a heart muscle disorder defined by the presence of a dilated and poorly functioning left ventricle in the absence of abnormal loading conditions (hypertension, valve disease) or ischaemic heart disease sufficient to cause global systolic impairment. The main objective of our study is to evaluate the changes of heart wall by gross morphometric measurements in DCM patient's heart samples and compare these with the control heart samples and our study is mainly focused in the regions of North India. Previous studies do not sufficiently reveal the anatomical variation of the heart musculature wall in DCM patients from North India.

Copy Right, IJAR, 2017,. All rights reserved.

\section{Introduction:-}

Cardiomyopathy represents a diverse group of heart muscle disorders, which are further subdivided on the basis of their anatomic and hemodynamic findings. More than $80 \%$ of cardiomyopathies are classified as dilated or congestive. These disorders increase both myocardial mass and volume, such that, despite moderate myocyte enlargement, or hypertrophy, the heart appears thin walled and distended. Diminished contractile function is the critical hemodynamic feature of dilated cardiomyopathy, an abnormality that triggers complex neurohumoral responses, which increase circulatory volume so as to maintain cardiac output. Although such events are initially compensatory, these responses ultimately become maladaptive and contribute to clinical deterioration and onset of heart failure. Only $50 \%$ of patients with dilated cardiomyopathy survive 15 years after diagnosis ${ }^{1}$; premature death occurs from unmitigated pump failure and from co-morbidities such as thromboembolic events and arrhythmias. Despite current strategies to aggressively manage dilated cardiomyopathy, the disorder remains a common cause of heart failure and a prevalent diagnosis in individuals referred for cardiac transplantation.

Exact prevalence of DCM in India is not known. The incidence of dilated cardiomyopathy discovered at autopsy is estimated to be 4.5 cases per 100,000 populations per year, whereas the clinical incidence is 2.45 cases per 100,000 populations per year ${ }^{2}$. The disease is reported to be more prevalent and aggressive in Blacks and in females, while a few other reports had shown a preponderance of males.

The main objective of our study is to evaluate the changes of heart wall by gross morphometric measurements in DCM patients and compare these with the control heart samples and this study is mainly focused in North Indian patients. Previous studies do not sufficiently reveal the anatomical variation of the heart musculature wall in DCM patients from North India. 


\section{Materials And Methods:-}

The present study was carried in the Department of Anatomy, Institute of Medical Sciences, Banaras Hindu University, Varanasi (U.P), over a period of one and a half year starting from November 2013 to June 2015 . In our study, measurements of heart samples (Control versus Dilated cardiomyopathy) with the help of Vernier Caliper were carried out. The thickness of wall of all the four compartments of heart samples (both Control and DCM) were measured with the help of Vernier Caliper. 60 human hearts were taken for the study. The age was in the range of 10-70 years whereas the cause of death of most of them was unknown. We procured heart samples from Department of Forensic Medicine and Department of Anatomy, Institute of Medical Sciences, BHU, Varanasi (U.P). All necessary consents were taken prior to the commencement of our study. Hearts with gross morphological variations were excluded from study.

\section{Dissection of the heart:-}

Firstly the heart samples were properly washed with water and then the left ventricular chambers were opened by giving a longitudinal incision starting from left auricle up to the apex of heart. Clots were removed and the chambers were washed under running tap-water.

To open the left atrium, incision was made from pulmonary vein opening up to the left auricle. For right atrium, incision was given from superior vena cava opening up to the right auricle and for right ventricle, incision was further extended beyond the right auricle up to the apex of heart. Again the heart chambers were properly washed under running tap-water to remove any clots. With the help of Vernier Caliper, we measured the thickness of all the four chambers of heart and made entries in the table.

\section{Results:-}

\section{Gross Findings:-}

Thickness of Walls of Chambers of Heart Samples:-

Out of the 60 hearts collected, 10 were of DCM and 50 were controls. Thickness of the walls of all the four chambers of the heart were measured and comparison was made between DCM hearts and control hearts. The thickness of left ventricular wall of DCM hearts was $8.640 \pm 1.696 \mathrm{~mm}$ (Mean \pm SD), with range 5.900-10.20 mm whereas that of Control hearts was $13.37 \pm 1.245 \mathrm{~mm}(\mathrm{Mean} \pm \mathrm{SD})$, with range 11.20-16.20 mm. The decrease in the thickness was significantly reduced with p-value of $<0.0001$ (Table 1 and Figure 1). In case of right ventricular wall thickness, the DCM hearts measured 6.020 $\pm 0.524 \mathrm{~mm}$ (Mean \pm SD), with range 5.200-6.900 mm whereas Control hearts measured 6.720 $\pm 0.774 \mathrm{~mm}(\mathrm{Mean} \pm \mathrm{SD})$, with range 5.100-8.400 mm which exhibited a significant difference on unpaired t test with a p-value of 0.0084 (Table 1 and Figure 1). In case of left atrial wall thickness, the DCM hearts measured 2.860 $\pm 0.558 \mathrm{~mm}$ (Mean $\pm \mathrm{SD}$ ), with range 2.200-3.800 mm and Control hearts measured $2.892 \pm 0.576 \mathrm{~mm}$ (Mean $\pm \mathrm{SD}$ ), with range 1.800-3.900 $\mathrm{mm}$ which showed a non significant difference on unpaired $\mathrm{t}$ test with a p-value of 0.8726 (Table 1and Figure 1). However in case of right atrial wall, the thickness of DCM

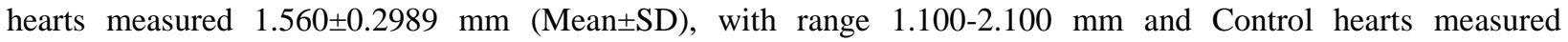
$1.870 \pm 0.4621 \mathrm{~mm}($ Mean $\pm \mathrm{SD})$, with range 1.100-2.900 $\mathrm{mm}$ which exhibited a significant difference on unpaired $\mathrm{t}$ test with a p-value of 0.0469 (Table1 and Figure 1).

Table 1:- The normal verses the dilated cardiomyopathy heart parameters exhibiting the thickness of all the four chambers of heart samples. Unpaired t test was used to evaluate the statistical difference .

\begin{tabular}{|c|c|c|c|c|c|c|c|c|}
\hline & \multicolumn{2}{|c|}{ Right Atrium } & \multicolumn{2}{|c|}{ Left Atrium } & \multicolumn{2}{|c|}{ Right Ventricle } & \multicolumn{2}{|c|}{ Left ventricle } \\
\hline & DCM & CONTROL & DCM & CONTROL & DCM & CONTROL & DCM & CONTROL \\
\hline $\begin{array}{l}\text { Number } \\
\text { of Values }\end{array}$ & 10 & 50 & 10 & 50 & 10 & 50 & 10 & 50 \\
\hline $\begin{array}{l}\begin{array}{l}\text { Range } \\
(\mathrm{mm})\end{array} \\
\end{array}$ & $\begin{array}{l}1.100- \\
2.100\end{array}$ & $1.100-2.900$ & $\begin{array}{l}2.200- \\
3.800\end{array}$ & $1.800-3.900$ & $\begin{array}{l}5.200- \\
6.900\end{array}$ & 5.100-8.400 & $\begin{array}{l}5.900- \\
10.20\end{array}$ & $11.20-16.20$ \\
\hline IQR & $\begin{array}{l}1.350- \\
1.750\end{array}$ & $1.500-2.200$ & $\begin{array}{l}2.275- \\
3.425\end{array}$ & 2.475-3.325 & $\begin{array}{l}5.675- \\
6.350\end{array}$ & 6.100-7.300 & $\begin{array}{l}\text { 6.675- } \\
10.00\end{array}$ & $12.55-14.45$ \\
\hline Median & 1.550 & 1.800 & 2.800 & 2.800 & 5.950 & 6.700 & 9.600 & 12.80 \\
\hline Mean & 1.560 & 1.870 & 2.860 & 2.892 & 6.020 & 6.720 & 8.640 & 13.37 \\
\hline $\begin{array}{l}\text { Satndard } \\
\text { deviation }\end{array}$ & 0.2989 & 0.4621 & 0.5582 & 0.5764 & 0.5245 & 0.7743 & 1.696 & 1.245 \\
\hline Satndard & 0.09452 & 0.06536 & 0.1765 & 0.08151 & 0.1659 & 0.1095 & 0.5363 & 0.1761 \\
\hline
\end{tabular}




\begin{tabular}{|c|c|c|c|c|c|c|c|c|}
\hline error & & & & & & & & \\
\hline $\begin{array}{l}\text { Lower } \\
95 \% \text { CI of } \\
\text { mean }\end{array}$ & 1.346 & 1.739 & 2.461 & 2.728 & 5.645 & 6.500 & 7.427 & 13.01 \\
\hline $\begin{array}{l}\text { Upper } \\
95 \% \text { CI of } \\
\text { mean }\end{array}$ & 1.774 & 2.001 & 3.259 & 3.056 & 6.395 & 6.940 & 9.853 & 13.72 \\
\hline $\begin{array}{l}\text { Unpaired } \\
\text { t test }\end{array}$ & & & & & & & & \\
\hline P value & & 0.0469 & & 0.8726 & & 0.0084 & & $<0.0001$ \\
\hline $\begin{array}{l}\text { Are } \\
\text { means } \\
\text { signif. } \\
\text { different? } \\
(P<0.05)\end{array}$ & & Yes & & No & & Yes & & Yes \\
\hline $\begin{array}{l}\text { One- or } \\
\text { two-tailed } \\
P \text { value? } \\
\text { Two- } \\
\text { tailed }\end{array}$ & & Two-tailed & & Two-tailed & & Two-tailed & & Two-tailed \\
\hline
\end{tabular}

DCM vs CONTROL

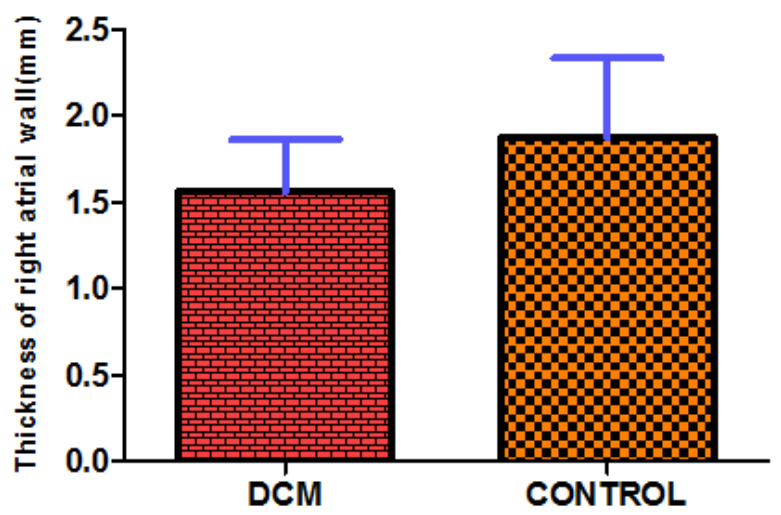

DCM vs CONTROL

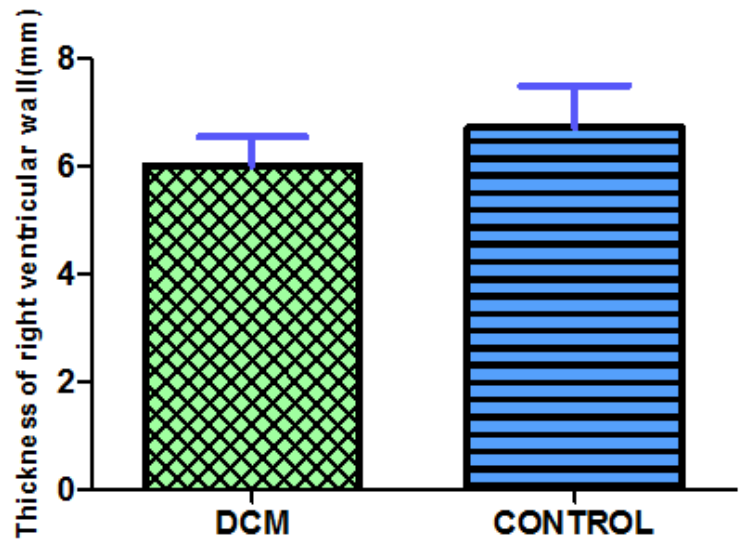

DCM vs CONTROL

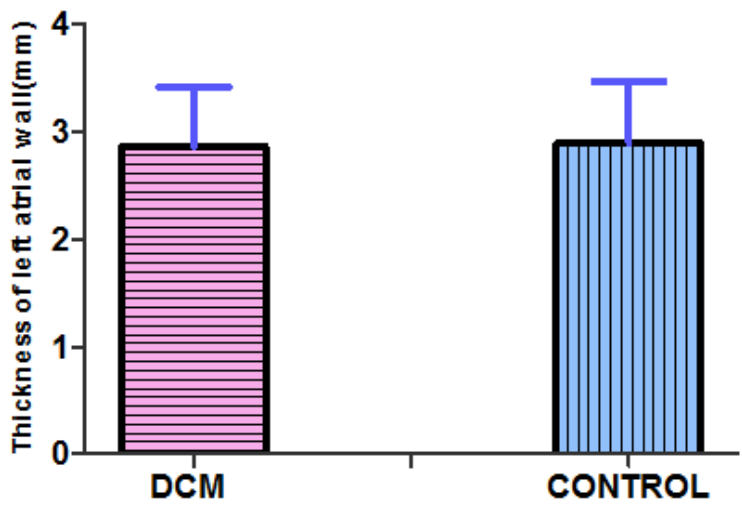

DCM vs CONTROL

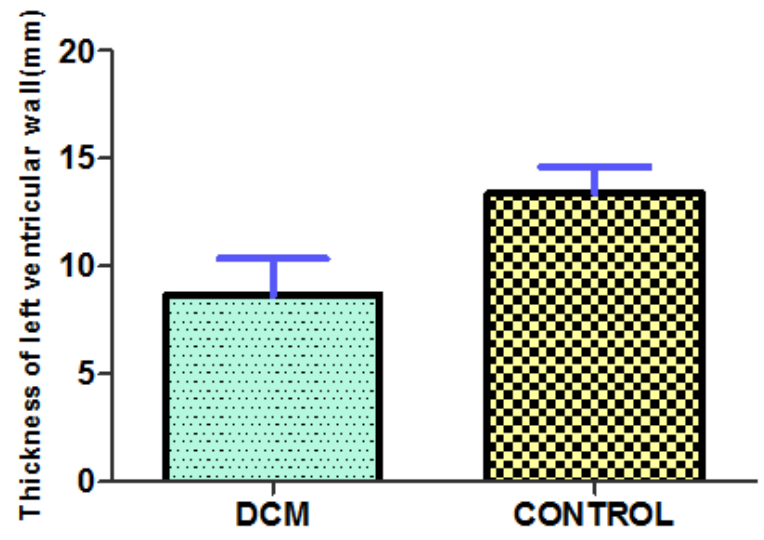

Fig 1:- Comparison of thickness of all the four chambers of heart samples of DCM and Control. 


\section{Weight of Heart Samples:-}

Out of 60 heart samples, the weight of 10 DCM heart samples was $726.6 \pm 86.38$ grams whereas those of control was only $278 \pm 84.49$ grams with a p-value of $<0.0001$ which indicates that the two groups were statistically different and weight gets increased in case of Dilated Cardiomyopathy (Table 2). The same thing was explained with the help of bar diagram in Figure 2.

Table 2:- The normal verses the dilated cardiomyopathy heart parameters exhibiting the weight of hearts. Unpaired $t$ test was used to evaluate the statistical difference.

\begin{tabular}{|l|l|l|}
\hline & \multicolumn{1}{|c|}{ DCM } & \multicolumn{1}{c|}{ CONTROL } \\
\hline Number of values & 10 & 50 \\
\hline & & \\
\hline Minimum- Maximum & $596.0-832.0$ & $178.0-512.0$ \\
\hline 25\% Percentile-75\% Percentile & $647.5-814.0$ & $209.5-320.3$ \\
\hline Median & 738.0 & 260.5 \\
\hline & & \\
\hline Mean & 726.6 & 278.8 \\
\hline Std. Deviation & 86.38 & 84.49 \\
\hline Std. Error & 27.32 & 11.95 \\
\hline & & \\
\hline Lower 95\% CI of mean & 664.8 & 254.8 \\
\hline Upper 95\% CI of mean & 788.4 & 302.9 \\
\hline & & \\
\hline Unpaired t test & & \\
\hline P value & & $<0.0001$ \\
\hline Are means signif. different? (P $<0.05)$ & & Yes \\
\hline One- or two-tailed P value? & & Two-tailed \\
\hline
\end{tabular}

\section{DCM vs CONTROL}

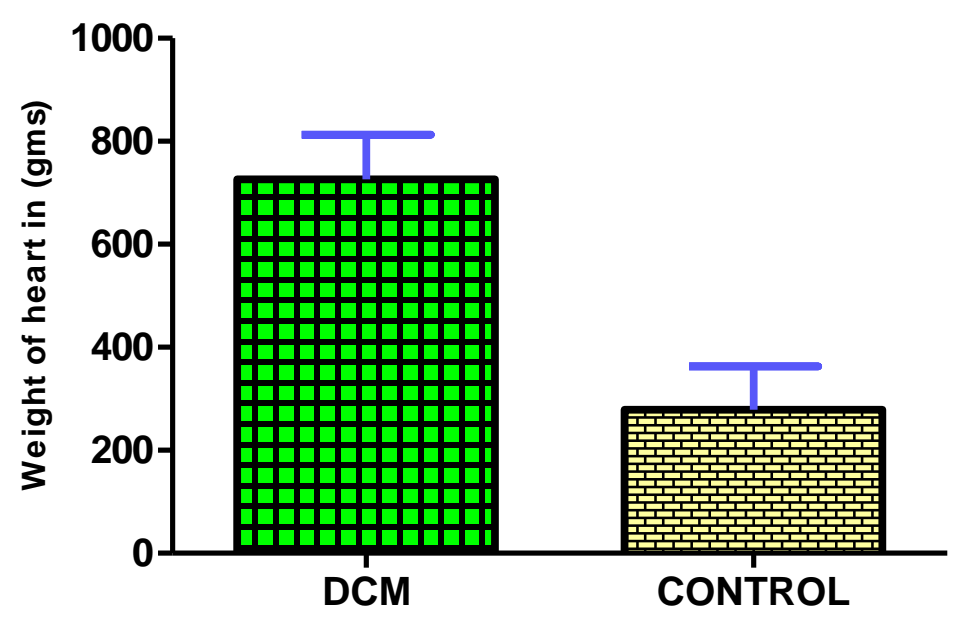

Fig 2:- Comparison of weight of hearts between DCM and Control 


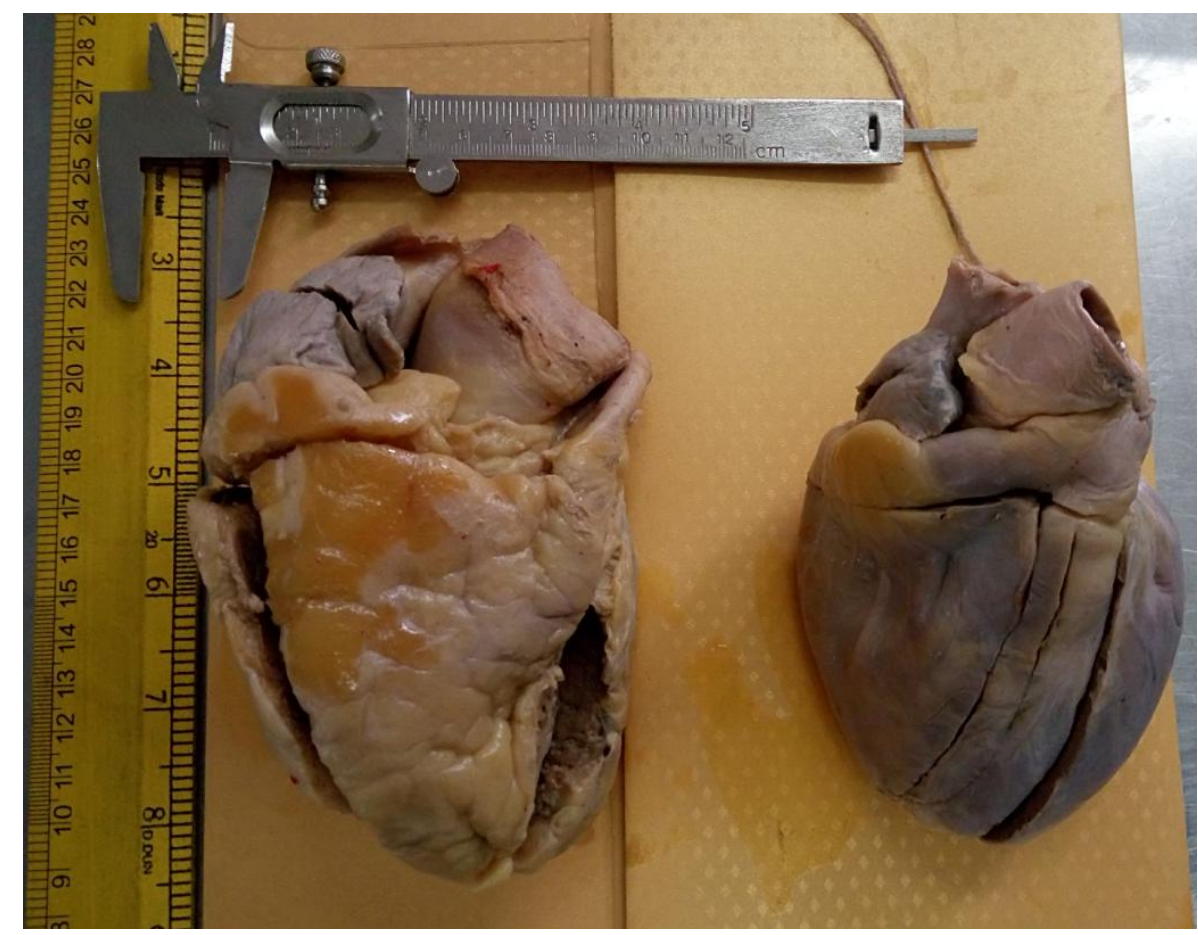

Fig 3:- Picture showing a big dilated cardiomyopathy heart (Left) and a normal heart (Right).
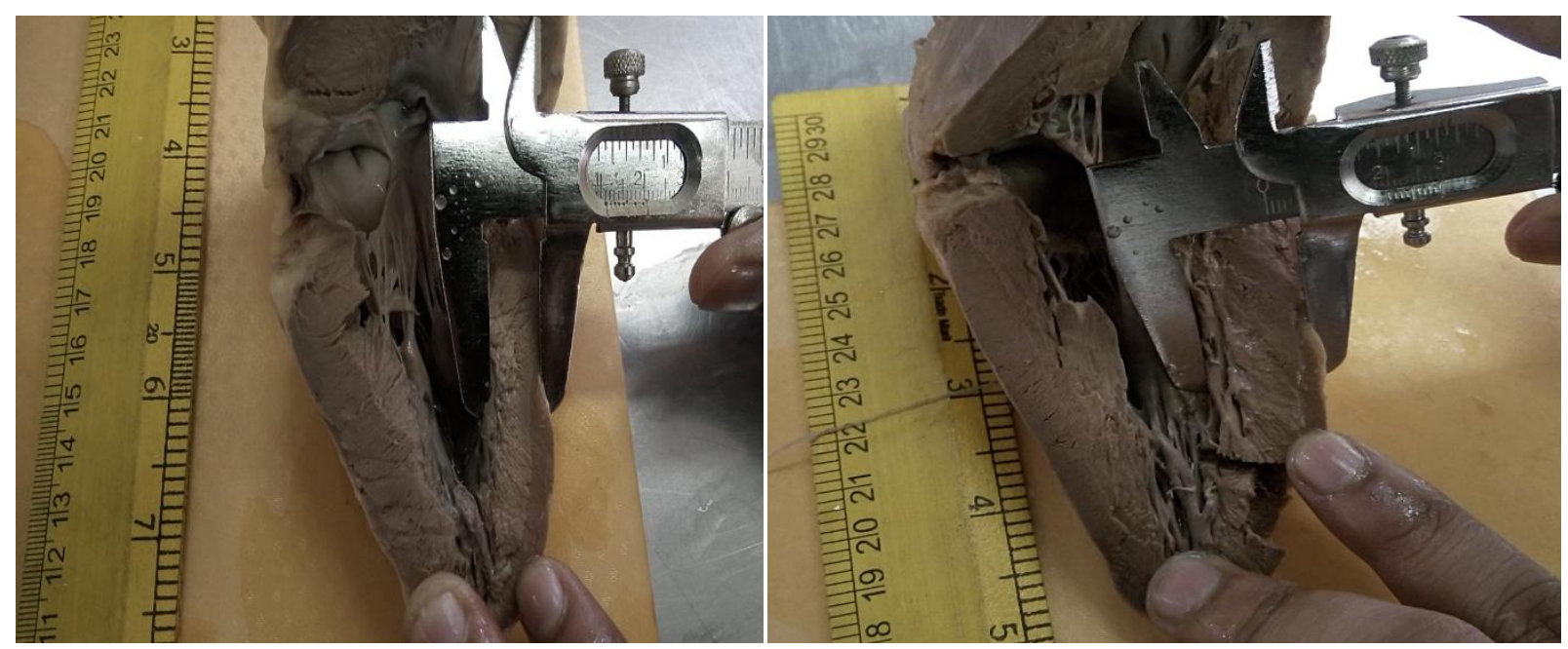

Fig 4:- Picture showing the thickness of left ventricular wall of a dilated cardiomyopathy heart (Left) and a normal heart (Right) being measured with the help of Vernier Caliper. 


\section{Discussion:-}

Defined by ventricular dilation and diminished contractile function, dilated cardiomyopathy is a prevalent worldwide disorder that is estimated to affect 36.5 per 100,000 individuals ${ }^{3}$. DCM results in heart failure, serious arrhythmias and thromboembolic events which ultimately proves fatal for the affected individual. The pathologic manifestations of dilated cardiomyopathy are often nonspecific. Although cardiac mass is increased, there is often only modest ventricular wall hypertrophy while atrial and ventricular chambers can be mildly or markedly distended.

Signs and symptoms in the early stages of DCM are vague and the affected person shows symptoms of easy fatigue, dyspnea or palpitations. Further deterioration in contractile function and progression toward heart failure or onset of atrial and ventricular arrhythmias worsens symptoms. Diagnosis of dilated cardiomyopathy is based on the finding of increased cardiac systolic and diastolic dimensions with diminished contractile function. When underlying causes such as coronary artery disease, chronic alcohol abuse, thyroid disease, or viral infection are excluded as etiologies, a diagnosis is often made of idiopathic dilated cardiomyopathy ${ }^{4}$. Over the past decade, family studies ${ }^{5}$ and echocardiographic evaluations of relatives of affected individuals have demonstrated that approximately $25 \%-30 \%$ of "idiopathic" dilated cardiomyopathy is caused by an inherited gene mutation.

A morphologic examination of myocardial tissuewas performed in 60 heart samples. Out of the 60 heart samples, 10 samples were found dilated and their size was also bigger. Thickness of wall of all the chambers of all heart samples were measured with the help of Vernier Caliper.The thickness of left ventricular wall of DCM hearts was $8.640 \pm 1.696 \mathrm{~mm}(\mathrm{Mean} \pm \mathrm{SD})$ whereas that of Control hearts was $13.37 \pm 1.245 \mathrm{~mm}$ with p-value of $<0.0001$.In case of right ventricular wall thickness, the DCM hearts measured $6.020 \pm 0.524 \mathrm{~mm}$ whereas Control hearts measured $6.720 \pm 0.774 \mathrm{~mm}$ with $\mathrm{p}$-value of 0.0084.In case of left atrial wall thickness, the DCM hearts measured $2.860 \pm 0.558$ $\mathrm{mm}$ and Control hearts measured $2.892 \pm 0.576 \mathrm{~mm}$ with p-value of 0.8726 .And in case of right atrial wall, the thickness of DCM hearts measured $1.560 \pm 0.2989 \mathrm{~mm}$ and Control hearts measured $1.870 \pm 0.4621 \mathrm{~mm}$ with p-value of 0.0469. All these findings are in line with the previous studies that in DCM the thickness of the wall of left ventricle gets reduced. Similarly when the weight was measured, the DCM heart samples showed increase in weight.Our study showed that the weight of 10 DCM heart samples was $726.6 \pm 86.38$ grams whereas those of controls was only $278 \pm 84.49$ grams with a p-value of $<0.0001$.

Although the pathophysiology of DCM is well known ${ }^{6}$, the underlying genetic mechanism for this disorder has remained unclear. Whether the disease results from inflammation, autoimmune, or genetic causes has been speculated upon for decades ${ }^{7}$ but a unifying mechanism has not been proved. During the past several years, however, a variety of clues to the underlying cause of DCM, as well as the underlying basis for other inherited cardiovascular diseases, have emerged.

\section{Conclusion:-}

DCM is the most common cardiomyopathy, occurring primarily due to genetic defects or secondarily as a consequence of multiple factors, including long-standing hypertension, ischaemic heart disease, infection and sarcoidosis. For a doctor, it is very important to differentiate between familial DCM, idiopathic DCM and the other aetiologies, since managementdiffers for each. Mainstay of the treatment is early intervention and accurate diagnosis. While a great deal of progress for IDCM and FDCM has been made in discovering genetic cause and providing guidelines for its management, much more immense research is needed, including genetic discovery and medical management of specific types of genetic DCM.As with other genetic disorders, the study of DCM is undergoing a revolution, with execution of newer, massively parallelnext-generation sequencing. Clinical and genetic characterization of the inherited cardiomyopathies has lead to novel pathophysiological insights and a new realtime approach to genetic diagnosis.

\section{Acknowledgment:-}

This study is a part of my thesis and I am grateful to ICMR (Indian Council Of Medical Research) for providing the grant for my thesis and for their full support and cooperation. 


\section{References:-}

1. Grogan M, Redfield MM, Bailey KR,et al., Long-term outcome of patients with biopsy proven myocarditis: comparison with idiopathic dilated cardiomyopathy. J Am CollCardiol. 1995;26:80-4.

2. Rakar S, Di Lenarda A, PolettiA, Bussani R, Silvestri F, Camerini F. Epidemiology of dilated cardiomyopathy:A prospective post-mortem study of 5252 necropsies. Eur Heart J. 1997;18(1):117-23.

3. Cohn JN, Bristow MR, Chien KR, Colucci WS, Frazier OH,Leinwand LA,Lorell BH, Moss AJ, Sonnenblick $\mathrm{EH}$, Walsh RA, et al., Report of the National Heart, Lung and Blood Institute special emphasis panel on heart failure research. Circulation. 1997;95:766-70.

4. Seidman JG and Seidman C.The Genetic Basis for Cardiomyopathy: from Mutation Identification to Mechanistic Paradigms. Cell. 2001;104:557-67.

5. Grünig E, Tasman JA, Kucherer H, Franz W, Kubler W, Katus HA. Frequency and phenotypes of familial dilated cardiomyopathy. J Am CollCardiol. 1998;31:186-94.

6. Kasper EK et al.,The causes of dilated cardiomyopathy: a clinicopathologic review of 673 consecutive patients. J Am CollCardiol. 1994;23:586-90.

7. Bender J.R. Idiopathic dilated cardiomyopathy. An immunologic, genetic, or infectious disease, or all of the above? Circulation. 1991;83:515-22. 